\title{
Pollination ecology of the Gray Nicker CaEsalpinia CRISTA (CAESALPINIACEAE) A MANGROVE ASSOCIATE AT CORINGA MANgrove Forest, ANDhra PRADESH, INDIA
}

\author{
P. Suvarna Raju ${ }^{1} \&$ A.J. Solomon Raju ${ }^{2}$ \\ 1,2 Department of Environmental Sciences, Andhra University, Visakhapatnam, Andhra Pradesh 530003, India \\ ${ }^{1}$ suvarnarajup@rediffmail.com, ${ }^{2}$ ajsraju@yahoo.com (corresponding author)
}

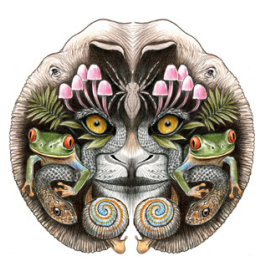

ISSN

Online 0974-7907

Print 0974-7893

OPEN ACCESS

Abstract: Caesalpinia crista L., commanly known as Gray Nicker, is an oligohaline mangrove associate confined to landward marginal areas of the Coringa Mangrove Forest, Andhra Pradesh, India. The flowering occurs during the wet season from June to November. The flowers are hermaphroditic, self-compatible and exhibit a mixed breeding system. The floral characteristics that constitute melittophilous pollination syndrome include diurnal anthesis, slight fragrance, zygomorphy, yellow petals, with a flag petal displaying a conspicuous nectar guide, and the presence of nectar with a high sugar concentration. Extra-floral nectar along the rachis is an additional attractant and is easily perceivable by bees. The plant is pollinated almost exclusively by bees, especially carpenter bees. The floral characteristics such as free petals, fully exposed stamens with dry and powdery pollen grains and hairy stigma facilitate anemophily which is effective due to high winds during the rainy season. The prolific growth and near synchronous flowering at population level contribute to pollen availability in huge quantities and enable anemophily as an effective mode of pollination. The functionality of melittophily and anemophily together constitutes ambophily. Hand-pollination experiments indicated that the plant is principally out-crossing. The natural fruit set does not exceed $10 \%$; this lowest percentage could be partly due to flower-feeding by the beetle, Mylabris phalerata. The fruits are indehiscent, 1-seeded, which are buoyant and are not dispersed far away from the parental sites. The viable seeds produce new plants in the vicinity of parental plants during the rainy season. This plant builds up its population as small patches or in pure stands and hence is important in building landward mangrove cover.

Keywords: Ambophily, Caesalpinia crista, Gray Nicker, mixed breeding system, self-compatibility.
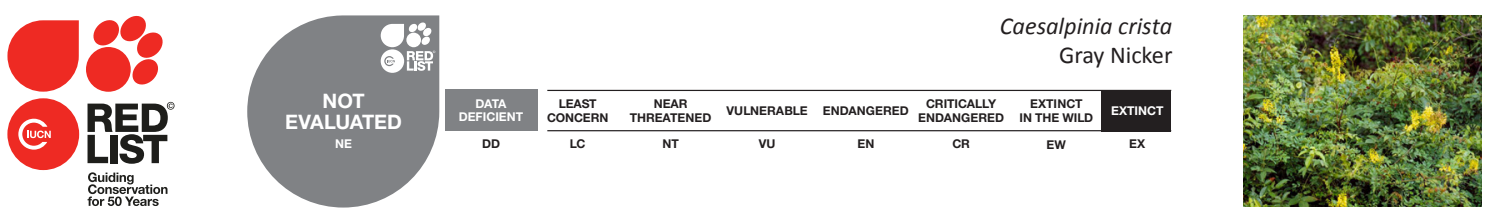

DOI: http://dx.doi.org/10.11609/JoTT.o3754.6345-54

Editor: Cleofas Cervancia, University of Philippines Los Baños College Laguna, Philippines.

Date of publication: 26 September 2014 (online \& print)

Manuscript details: Ms \# 03754 | Received 23 August 2013 | Final received 30 August 2014 | Finally accepted 01 September 2014

Citation: Raju, P.S. \& A.J.S. Raju (2014). Pollination ecology of the Gray Nicker Caesalpinia crista (Caesalpiniaceae) a mangrove associate at Coringa Mangrove Forest, Andhra Pradesh, India. Journal of Threatened Taxa 6(10): 6345-6354; http://dx.doi.org/10.11609/JoTT.03754.6345-54

Copyright: (c) Raju \& Raju 2014. Creative Commons Attribution 4.0 International License. JoTT allows unrestricted use of this article in any medium, reproduction and distribution by providing adequate credit to the authors and the source of publication.

Funding: Self-funded.

Competing Interest: The authors declare no competing interests.

Author Contribution: Both the authors contributed to a similar extent overall.

Author Details: P. SUVARNA RAJU has been awarded PhD under Prof. A.J. Solomon Raju. He is currently doing post-doctoral research. PROF. A.J. Solomon RAJU is Head of the Department of Environmental Sciences, Andhra University, Visakhapatnam. He is presently working on endemic and endangered plant species in southern Eastern Ghats forests with financial support from MoEF and CSIR.

Acknowledgements: We thank Andhra University for providing the necessary administrative help and the State Forest Department, Government of Andhra Pradesh for permission to work in the Coringa Mangrove Forest. 


\section{INTRODUCTION}

Caesalpinia is a genus of Caesalpiniaceae family. It is pantropical with 120-150 species of trees, shrubs, and lianas, but the study of the pollination ecology of the genus is so far limited to the New World species (Lewis 1998). A few species of Caesalpinia have been studied with regard to their pollination: C. pulcherrima (Ali 1932; Cruden \& Hermann-Parker 1979; Bullock 1985); C. gilliesii (Coccuci et al. 1992); C. calycina and C. pluviosa var. sanfranciscana (Lewis \& Gibbs 1999). Four flower types occur in Caesalpinia, each of which is adapted to a different pollinator (bee, butterfly, moth and hummingbird) suggesting that the floral character suites in the segregated species of Caesalpinia may be closely related to the type of pollinators (Vogel 1990; Shi-Jin et al. 2004). C. brevifolia, C. coriaria, C. echinata, C. sappan and $C$. spinosa are self-compatible, out-crossing and bee-pollinated (Roubik 1995).

In the Caesalpinia genus, only two species, namely, C. bonduc (Gray Nicker) and C. crista (Gray Nicker) extend into beach vegetation and are frequently found to be mangrove associates; one is pantropical and the other Asian. C. bonduc is a coarse scrambling vine, and widely distributed partly because seeds can float and retain their viability in water for extended times. Its reproductive biology is not known. C. crista is a back-mangal spiny climber distributed from India and Ceylon through most of Southeast Asia to the Ryu-Kyu Islands, Queensland, and New Caledonia (Tomlinson 1986). A study by Shi-Jin et al. (2004) indicated that it is a hermaphroditic species and pollinated by wind and insects. But, the details of pollination ecology are not available and hence, the present study was contemplated with the objective of providing floral biology, breeding system, pollination system, and fruiting aspects of $C$. crista in order to understand the ability of this species to survive and form its population in the landward areas of Coringa mangrove forest in India.

\section{MATERIALS AND METHODS}

The Coringa Mangrove Forest covering an area of $188 \mathrm{~km}^{2}$ lies between $16^{\circ} 30^{\prime}-17^{\circ} 00^{\prime} \mathrm{N}$ and $82^{\circ} 10^{\prime}-$ $80^{\circ} 23^{\prime} \mathrm{E}$. It is located in the delta in East Godavari District; it is created by the River Godavari which is $1,330 \mathrm{~km}$ long and the second longest river in India. It branches into Vasishta and Gautami near Dowleswaram, which is considered as the head of the delta. Two distributaries Coringa and Gaderu branching-off the northern bank of the rivers, Gautami-Godavari, supply freshwater to the Coringa mangroves. Freshwater flows into the mangrove wetlands of the Godavari delta for a period of six months and peak flow normally occurs during July to September, coinciding with the southwest monsoon season. During this period the entire delta, including the mangrove wetland is submerged under freshwater, since penetration of sea water is completely blocked by the large amount of incoming freshwater. Brackish water condition prevails from October to February and sea water dominates the entire mangrove wetland from March to May due to the absence of freshwater discharge.

Caesalpinia crista is a prickly climber and is confined to landward localities of the mangrove forest. It is quite prominent during its flowering season due to its attractive bright yellow flowers. It is used in Ayurveda; the seeds, the leaves and the bark are used in the treatment of amenorrhoea, dysmenorrhoea, diabetes, intermittent fevers, febrifuge, anthelmintic, expectorant, as a uterine stimulant and to cleanse the uterus (Jabbar et al. 2007).

Field experiments were conducted on C. crista during the period from February 2010 to October 2012. Observations regarding the organization of inflorescences, the spatial positioning of flowers, and their position on the plant were made since these features are regarded as important for foraging and effecting pollination by flower-visitors. The flower longevity was recorded by marking twenty just open flowers and following them until they fell off. Anthesis was initially recorded by observing ten marked mature buds in the field. Later, the observations were repeated five times on different days, each day observing twenty marked mature buds in order to provide accurate anthesis schedule. The same marked mature buds were followed for recording the time of anther dehiscence. The presentation pattern of pollen was also investigated by recording how anthers dehisced and confirmed by observing the anthers under a $10 x$ hand lens. The details of flower morphology such as flower sex, shape, size, colour, odour, sepals, petals, stamens and ovary were described.

Twenty mature but un-dehisced anthers were collected from five randomly chosen plants and placed in a petri dish. Later, each time a single anther was taken out and placed on a clean microscope slide $(75 \times 25 \mathrm{~mm})$ and dabbed with a needle in a drop of lactophenolaniline-blue, the anther tissue was then observed under the microscope for pollen, if any, and if pollen grains were not there, the tissue was removed from the slide. The pollen mass was drawn into a band, and 
the total number of pollen grains was counted under a compound microscope (40x objective, 10x eye piece). This procedure was followed for counting the number of pollen grains in each anther collected. Based on these counts, the mean number of pollen produced per anther was determined. The mean pollen output per anther was multiplied by the number of anthers in the flower for obtaining the mean number of pollen grains per flower. The characteristics of pollen grains were also recorded. The pollen-ovule ratio was determined by dividing the average number of pollen grains per flower by the number of ovules per flower. The value thus obtained was taken as pollen-ovule ratio (Cruden 1977). The stigma receptivity was observed visually and by $\mathrm{H}_{2} \mathrm{O}_{2}$ test. In the visual method, the stigma physical state (wet or dry) and the unfolding of its lobes were considered to record the commencement of receptivity; withering of the lobes was taken as a loss of receptivity. $\mathrm{H}_{2} \mathrm{O}_{2}$ test as given in Dafni et al. (2005) was followed for noting stigma receptivity period.

The presence of nectar was determined by observing fifty mature buds and open flowers collected at random from 10 plants. Individual volumes of nectar was recorded for 25 flowers and then the average volume of nectar per flower was determined and expressed in $\mu$. The flowers used for this purpose were bagged at mature bud stage, opened after anthesis and squeezed nectar into micropipette to measure the volume of nectar. Nectar sugar concentration was also simultaneously determined using a Hand Sugar Refractometer (Erma, Japan).

Fifty flowers each from 10 randomly selected plants were used for each mode of breeding system. The flowers were emasculated prior to anther dehiscence and bagged for fruit set through apomixis. The stigmas were pollinated with the pollen of the same flower manually by using a brush; they were bagged for fruit set through manipulated autogamy. The flowers were fine-mesh bagged without hand pollination for fruit set through spontaneous autogamy. The emasculated flowers were hand-pollinated with the pollen of a different flower on the same plant; they were bagged and followed for fruit set through geitonogamy. The emasculated flowers were pollinated with the pollen of a different individual plant and bagged for fruit set through xenogamy. All these modes of pollination were followed for one month for calculating the percentage of fruit set in each mode. Twenty inflorescences consisting of 200 flowers were tagged on 20 plants prior to anthesis and followed for fruit and seed set rate in open-pollinations. Fruit maturation period, fruit dehiscence, seed dispersal and establishment were observed in detail.

The insects visiting the flowers were bees and a butterfly. They were observed carefully for 10 hours in a day for 15 days in different weeks during the flowering season. The hourly foraging visits of each bee species were recorded on 10 different days for which 30 inflorescences were selected. The data obtained was used to calculate the percentage of foraging visits made by each bee species per day and also to calculate the percentage of foraging visits of each category of bees per day in order to understand the relative importance of each bee species. Simultaneously, the bees were observed for their foraging behavior such as mode of approach, landing, probing behaviour, the type of forage they collect, contact with essential organs to result in pollination and inter-plant foraging activity. The bees were captured from the flowers from 1000$1200 \mathrm{hr}$ on five different days for pollen analysis in the laboratory. For each bee species, 10 specimens were captured and each specimen was washed first in ethyl alcohol and the contents stained with aniline-blue on a glass slide and observed under a microscope to count the number of pollen grains present. In case of pollen collecting bees, pollen loads on their corbiculae were separated prior to washing them. From pollen counts, the average number of pollen grains carried by each bee species was calculated to know the pollen carryover efficiency of different bees. A beetle was found to be the flower predator. A sample of 500 flowers collected from 75 inflorescences selected at random was used for calculating the flower predation rate by this beetle.

Plant, flower and fruit details together with insect foraging activity on flowers were photographed with a Nikon D40X Digital SLR (10.1 pixel) and a TZ240 Stereo Zoom Microscope with SP-350 Olympus Digital Camera (8.1 pixel). Magnus Compound Microscope - 5x, 10x, 40x and $100 x$ magnification was used for studying pollen characteristics.

\section{RESULTS}

\section{Phenology}

It is a large climber with glossy branchlets more or less armed with recurved prickles. It is a mangrove associate and characteristically restricted to the landward side. The flowering occurs en masse from June to November (Image 1a). An individual plant flowers for about three months. The flowers are produced in racemes which arise from leaf axils and also aggregated into terminal 


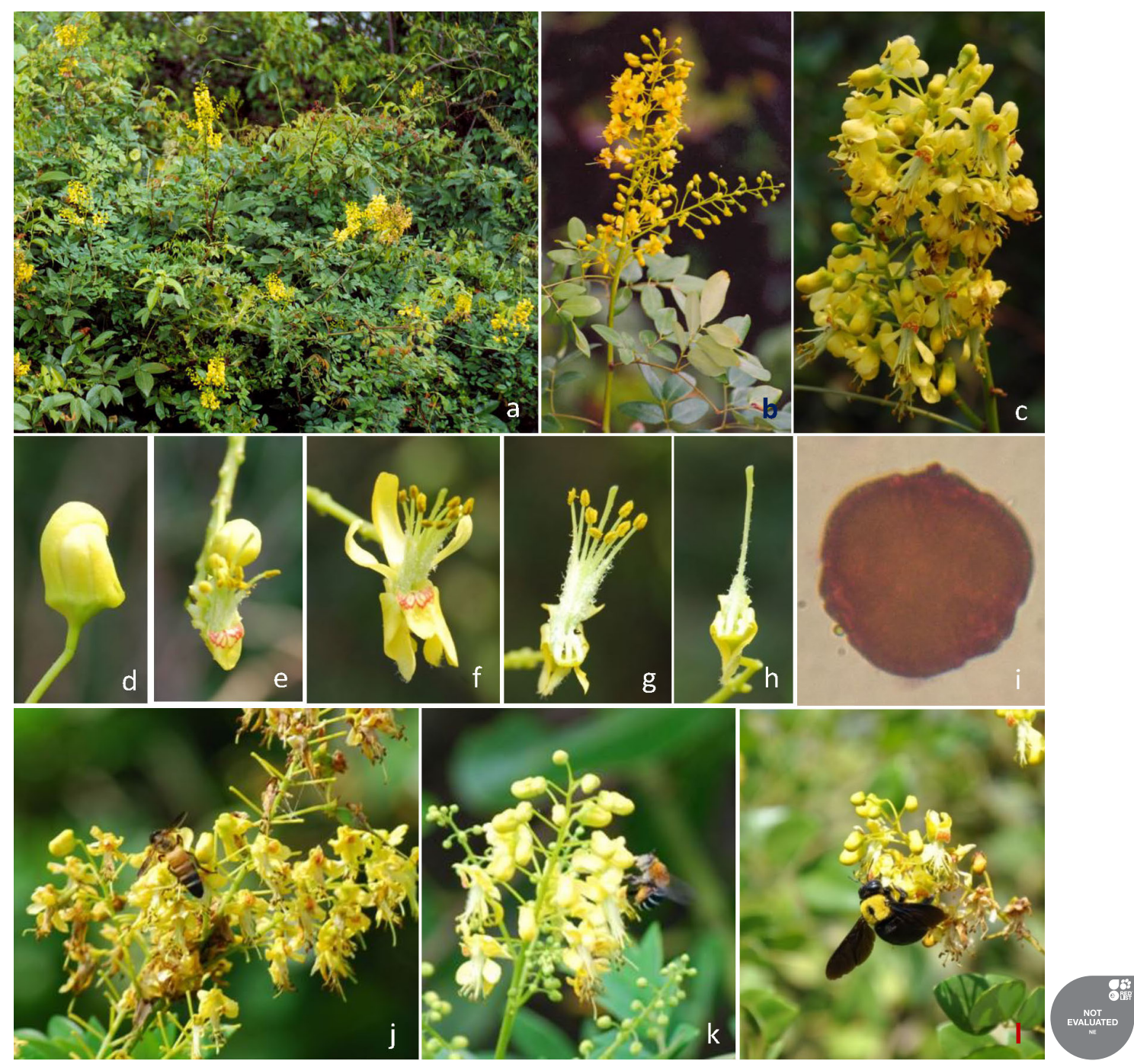

Image 1. Caesalpinia crista

a - Flowering tree; b-c - Flowering inflorescences; $d$ - Mature bud; e - Partial anthesis; f - Complete anthesis; $g$ - Relative positions of stamens and stigma; h - Stigma; I - Pollen grain; j - Apis dorsata; k - Amegilla sp.; I - Xylocopa pubescens. (C A.J. Solomon Raju

inflorescences. A raceme produces 33.26 \pm 6.1 (Range 27-42) flowers over a period of about ten days. Flower buds mature and open in an acropetal manner (Image $1 b, c)$. The plants begin leaf shedding during late winter and stays leafless until the new leaf flushing which occurs after the summer showers in May.

\section{The flower}

Flowers are pedicellate, gullet-shaped, small, $15 \mathrm{~mm}$ long, $10 \mathrm{~mm}$ wide, yellow, slightly fragrant, bisexual and zygomorphic. Calyx has five sepals, greenish yellow, $5 \mathrm{~mm}$ long, basally fleshy, thick and flattened, terminally curved into a boat-like structure and glabrous. The corolla is a bright yellow with five petals; the posterior petal is flag or banner-like with reddish nectar guide, flanked by two wing petals and two anterior petals. They are clawed, imbricate, $6 \mathrm{~mm}$ long, $4 \mathrm{~mm}$ wide and distinct. Stamens are 10, free, $8 \mathrm{~mm}$ long, filaments unequal, hairy and form a white and pubescent $12 \mathrm{~mm}$ long pseudotube at the base. The anthers are bilobed, light yellow, $1 \mathrm{~mm}$ long, exserted, introrse and versatile. Ovary is 1-carpelled with one locule and one ovule on marginal placentation. The style is $11 \mathrm{~mm}$ long, light green, glabrous with simple stigma, the rim of which is ciliated and chambered.

\section{Floral biology}

The mature buds open from $0600-1100 \mathrm{hr}$ by the unfolding of petal lobes. Petals expand horizontally but do not reflex; then the stamens, style and stigma 
are exposed (Image 1d-f). The style and stigma extend beyond the stamens (Image $1 \mathrm{~g}$ ). The anthers dehisce by longitudinal slits at anthesis. The pollen output per anther is $654 \pm 42.7$ (Range 598-726) and per flower, it comes to $6540 \pm 420.7$. Pollen grains are large, yellow, prolate, spheroidal, trizonocolporate, powdery and $49.8 \mu \mathrm{m}$ in size (Image 1i). The pollen-ovule ratio is $6,540: 1$. The stigma attains receptivity two hours after anther dehiscence; stigma is wet during the receptive period which extends until the evening of the second day (Image 1h). A flower produces 1.35 \pm 0.2 (Range 0.6-3.1) $\mu \mathrm{l}$ of nectar at the flower base and its access is restricted to the openings between the bases of the three upper stamens. The nectar sugar concentration is $30 \pm 2.35 \%$ (Range 20-34 \%). Extra-floral nectaries appear along the rachis and the nectar continues to secrete even after the flowers wither. The flowers fall off after 4-5 days in un-pollinated ones while the ovary remains and grows by gradual bulging to produce fruit in pollinated ones.

\section{Breeding systems}

The results of breeding systems indicate that the flowers are self-compatible and self-pollinating. Fruit set is $6 \%$ in autogamy (unmanipulated) $16 \%$ in autogamy (manipulated), $34 \%$ in geitonogamy while it is $62 \%$ in xenogamy and $9.5 \%$ in open-pollinations (Table 1 ).

\section{Pollination and Pollinators}

The flowers are unspecialized and the stamens and stigma become exposed when the petals expand horizontally. They were foraged on during day time
Table 1. Results of breeding experiments on Caesalpinia crista

\begin{tabular}{|l|c|c|c|}
\hline Breeding system & $\begin{array}{c}\text { No. of flowers } \\
\text { pollinated }\end{array}$ & $\begin{array}{c}\text { No. of flowers } \\
\text { set fruit }\end{array}$ & $\begin{array}{c}\text { Fruit set } \\
\text { (\%) }\end{array}$ \\
\hline Apomixis & 50 & 0 & 0 \\
\hline Autogamy (bagged) & 50 & 3 & 6 \\
\hline $\begin{array}{l}\text { Autogamy (hand- } \\
\text { pollinated and bagged) }\end{array}$ & 50 & 8 & 16 \\
\hline Geitonogamy & 50 & 17 & 34 \\
\hline Xenogamy & 50 & 31 & 62 \\
\hline Open pollinations & 200 & 19 & 9.5 \\
\hline
\end{tabular}

consistently from $0700-1700 \mathrm{hr}$. The foragers included bees, Apis dorsata (Image 1j), Pithitis binghami, Nomia sp., Amegilla sp. (Image 1k), Xylocopa pubescens (Fig. 1I), X. latipes (Image 2a) and Xylocopa sp. (Image 2b), Ceratina sp. (Image 2c), and the butterfly, Catopsilia Pomona (Image 2d). Of these, Xylocopa species and C. pomona collected only nectar while the other bees collected both nectar and pollen. Their foraging activity gradually increased from morning to evening with peak activity around noon time (Fig. 1). Of the total foraging visits made by both bees and the butterfly, $A$. dorsata and Ceratina sp. each made 15\%, P. binghami, X. pubescens and Amegilla sp. each 12\%, X. latipes 10\%, Xylocopa sp. 9\%, Nomia sp. $7 \%$ and C. pomona $8 \%$ (Fig. 2). Apis, Xylocopa and Amegilla bees were found to depress efficiently the anterior petals to access nectar while Pithitis and Nomia were found to have easy access to the nectar in flowers previously foraged by Xylocopa
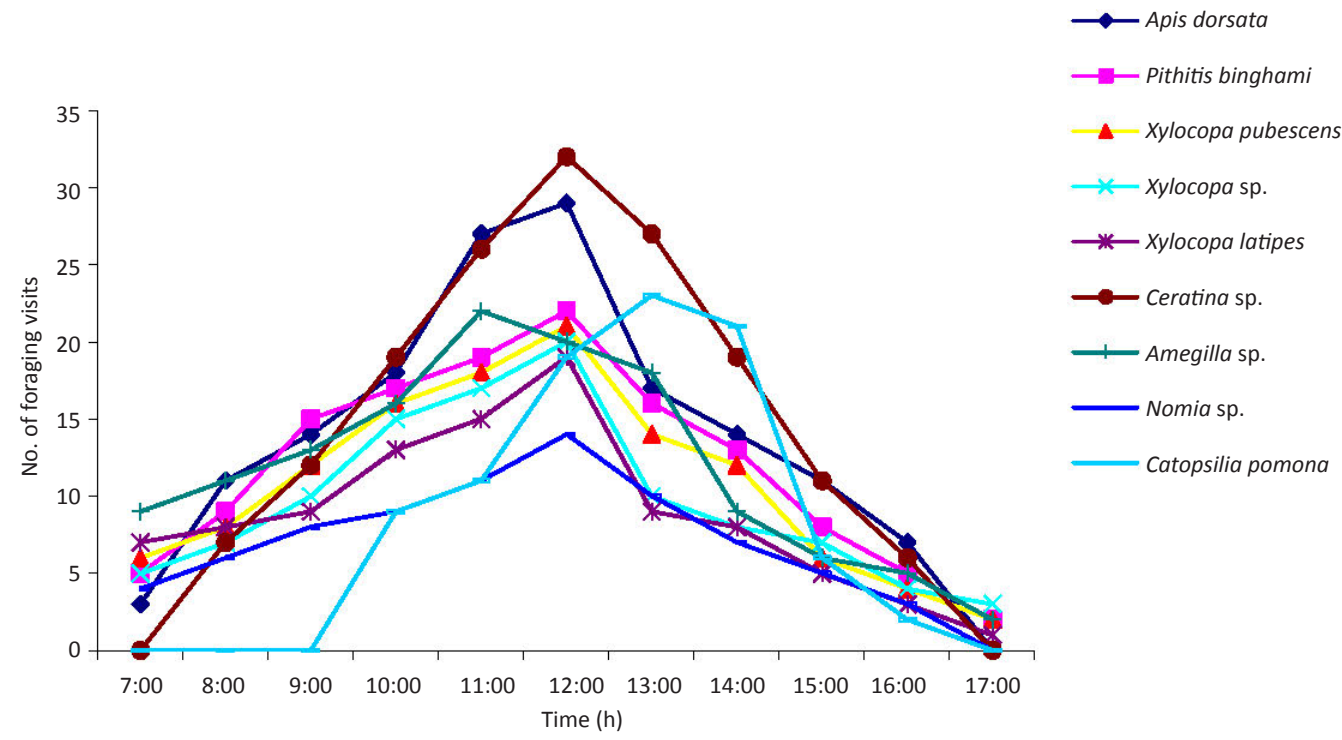

Figure 1. Hourly foraging activity of insects on Caesalpinia crista. 

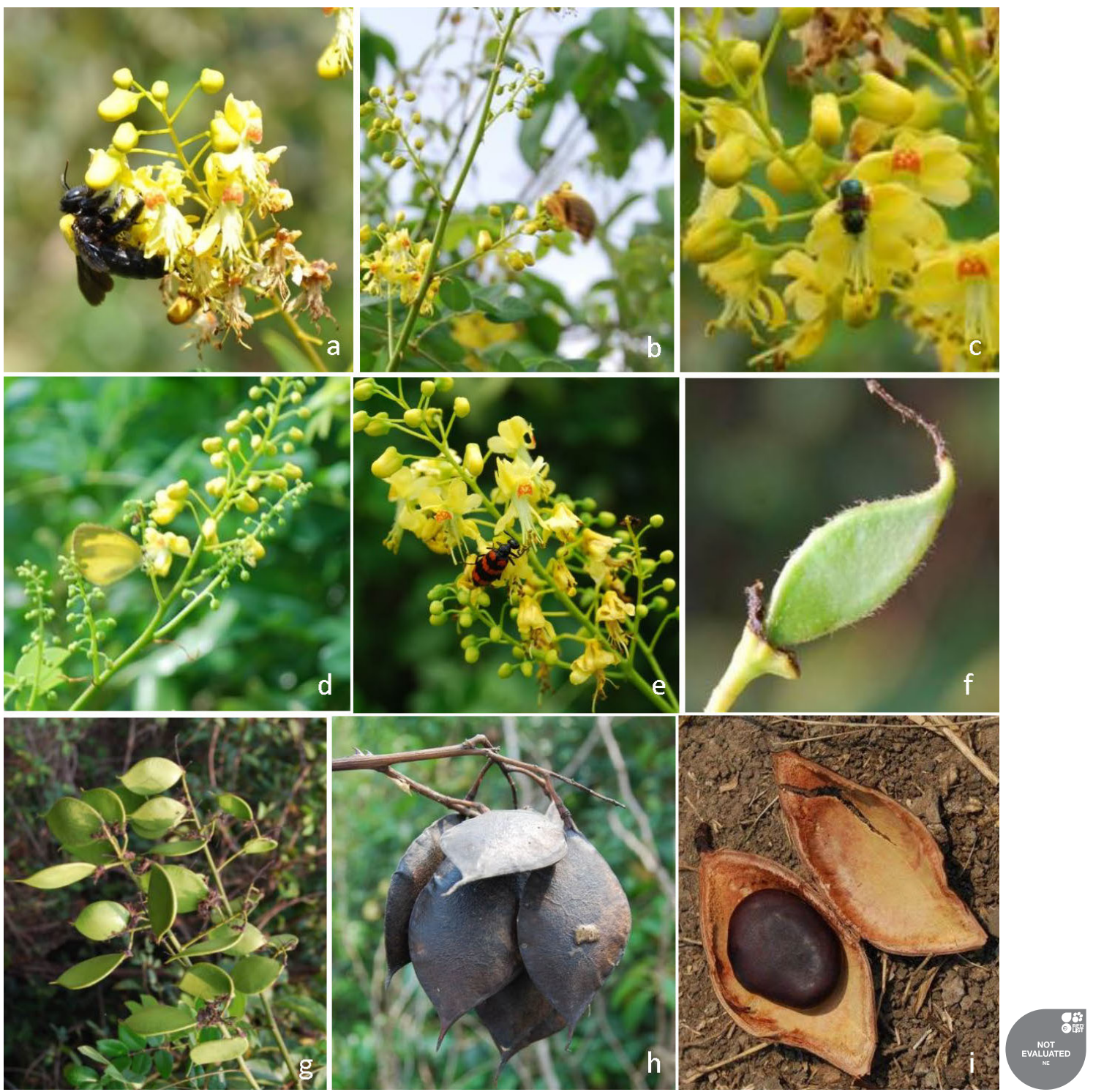

Image 2. Caesalpinia crista

a - Xylocopa latipes; b - Xylocopa sp.; c - Ceratina sp.; d - Catopsilia Pomona; e - Mylabris phalerata; f-h - Different stages of fruit development; I - 1-seeded pod. () A.J. Solomon Raju

and Amegilla. However, Pithitis, Nomia and Ceratina bees were found to collect pollen easily as the anthers are well exposed. Apis, Xylocopa and Amegilla while probing the flower for nectar and/or pollen invariably contacted the stamens and stigma. The other bees also collected both pollen and nectar but primarily concentrated on pollen collection during which their ventral side established contact with the stigma. Body washings of bees revealed the presence of pollen grains; the mean number varied from 123 to 494 (Table 2). The collection of nectar by bees led to the gradual reduction in the standing crop of nectar and hence they were compelled to visit as many flowers as possible from several plants during the day. The inter-plant activity was more during the afternoon period. Their foraging activity was found to be effecting both self- and crosspollination. The butterfly, C. pomona is not a consistent forager throughout the flowering season while the bees were consistent in their foraging activity throughout the flowering season. The butterfly mostly probed the flowers by stretching out the proboscis to the flower base to collect nectar during which it occasionally contacted the stamens and stigma and hence was not important as a pollinator. The nectar collecting bees also visited the extra-floral nectaries for nectar collection and this appeared to promote their foraging rate. 


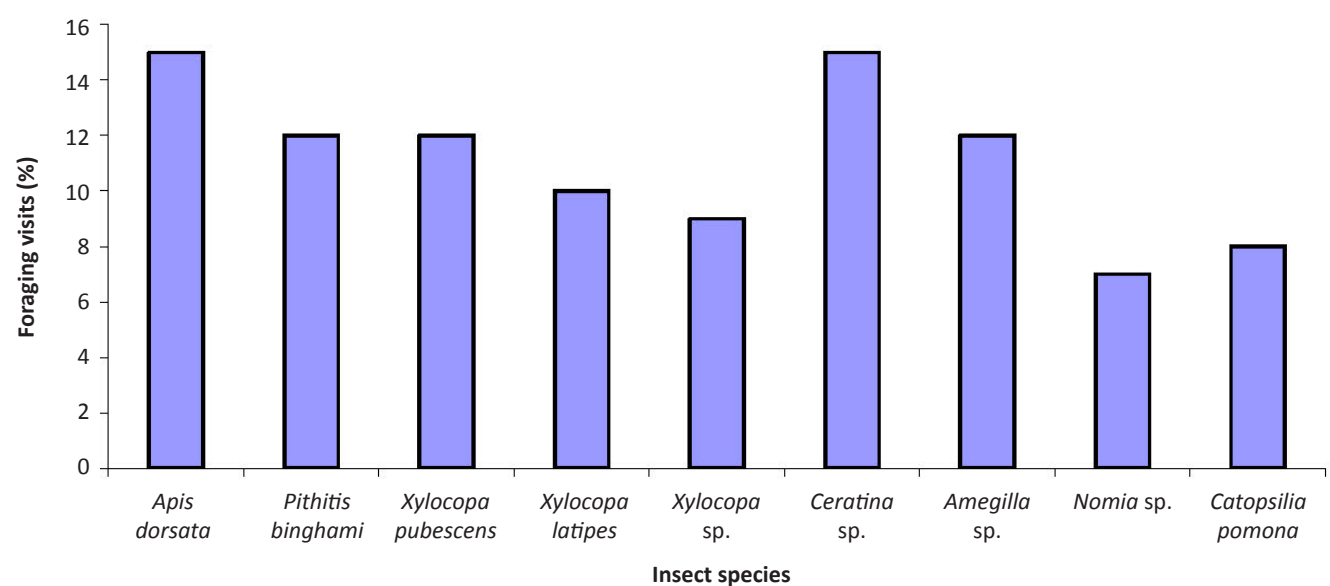

Figure 2. Percent foraging visits of insects on Caesalpinia crista.

Table 2. Pollen pick up efficiency of foraging bees on Caesalpinia crista

\begin{tabular}{|l|c|c|c|}
\hline Insect species & Sample size & Range & Mean \pm S.D \\
\hline Apis dorsata & 10 & $256-637$ & $312 \pm 131.23$ \\
\hline Pithitis binghami & 10 & $240-561$ & $433.2 \pm 114.36$ \\
\hline Xylocopa pubescens & 10 & $310-625$ & $494.0 \pm 105.40$ \\
\hline Xylocopa latipes & 10 & $291-593$ & $447.9 \pm 95.02$ \\
\hline Xylocopa sp. & 10 & $325-610$ & $478.9 \pm 91.37$ \\
\hline Ceratina sp. & 10 & $279-342$ & $123 \pm 64.43$ \\
\hline Amegilla sp. & 10 & $125-212$ & $174.4 \pm 31.64$ \\
\hline Nomia sp. & 10 & $162-376$ & $273.5 \pm 78.35$ \\
\hline
\end{tabular}

The locations of $C$. crista are windy during the rainy season during which flowering occurs. The rainy season is normally associated with gale or cyclonic winds. The pollen being dry and powdery especially on clear sunny days is exposed to the ambient air. The pollen is blown away by the wind on such days and it can be seen on the leaves; hence wind is also considered to be playing a role in effecting self- and cross-pollination.

\section{Flower predation}

Further, a beetle, Mylabris phalerata was found to feed on floral parts including stamens and stigma (Image $2 \mathrm{e})$; its flower-feeding behaviour was considered to be affecting reproductive success. The flower damage and subsequent drop rate due to this beetle feeding is $23 \%$.

\section{Fruiting behavior}

Pollinated and fertilized flowers initiate fruit development immediately and take six weeks to produce mature fruits (Image $2 \mathrm{f}-\mathrm{h}$ ). Fruit is a leguminous pod, oblong, 50-60 mm long, smooth, inflated with a leathery pericarp. It is 1-seeded, ovoid, $3 \mathrm{~cm}$ long, hard and gray-black with a shiny testa (Image $2 \mathrm{i}$ ). The pod is water-buoyant and dispersed by tidal currents. The fruit pericarp becomes fibrous, disintegrates gradually releasing the seed which in turn finally settles in the soil for germination and subsequent production of a new plant.

\section{DISCUSSION}

In Caesalpinia genus, only two species, namely, $C$. bonduc and $C$. crista extend their distribution into beach vegetation and are frequent mangrove associates. $C$. bonduc is a pantropical, coarse scrambling vine and has a wide distribution and such distribution is partly due to floating of its seeds in tidal waters and to the extended viability of seeds in water. C. crista is also a climber but is restricted to Asian beaches and mangroves (Tomlinson 1986). In Coringa mangroves, C. bonduc does not occur while $C$. crista grows profusely landward. The landward occurrence is an indication that this plant species is oligohaline with low salinity. The plant does not show up during the summer season due to the shedding of aerial parts. The summer monsoon showers trigger the leaf flushing process in this species, and once initiated, it continues into the rainy season. This event is immediately followed by flowering which extends into November. The leaf shedding occurs following the maturation of fruits in late winter. These sequential events are characteristics of $C$. crista and hence it is a typical seasonal plant. As a mangrove associate, $C$. crista is important for shoreline stabilization to bind the soil together. Its prolific growth during the rainy season stabilizes the soil and plays a prominent role in reducing 
soil erosion and landward penetration of seawater.

The genus Caesalpinia is pantropical and has a complex taxonomic history with more than 120 terrestrial species most of which are known for their ornamental and ecological values (Lewis 1998). The genus is poorly investigated concerning its reproductive biology. A few species have been studied for understanding their pollination biology and these studies are also mostly limited to the New World species (Lewis 1998; Lewis \& Gibbs 1999). The available information on pollination biology on Caesalpinia species indicates the operation of different pollination syndromes. C. calycina is andromonoecious while $C$. pluviosa is hermaphrodite; both are pollinated by carpenter bees (Lewis \& Gibbs 1999). C. coluteifolia, C. exilifolia, C. paraguariensis and C. eriostachys are all hermaphrodites and pollinated by carpenter bees (Jones \& Buchman 1974). C. brevifolia, $C$. coriaria, C. echinata, C. sappan and C. spinosa are beepollinated (Roubk 1995). C. pulcherrima is psychophilous and pollinated by a diverse species of diurnal butterflies (Cruden \& Hermann-Parker 1979). Nocturnal hawk moth pollination is reported in C. gilliesii (Cocucci et al. 1992), hummingbird-pollination in C. exostemma and C. conzattii (Vogel 1990; Borges et al. 2009), and bat-pollination in C. bahamensis (Koch et al. 2004). These reports indicate that Ceasalpinia species have different flower types adapted to different pollinator types suggesting that the floral characteristics in a given species are closely related to the pollinator type (Vogel 1990). On the contrary, based on floral characteristics and pollinator type, Lewis \& Gibbs (1999) reported that diverse groups occur within the genus Caesalpinia and melittophily is the most common mode among studied species and hence, it is likely to be the ancestral pollination syndrome. The changes in pollination syndrome are likely to have been acquired independently by evolution from melittophilous taxa within these groups after their differentiation from Caesalpinia. Lewis et al. (2000) also stated that bee-pollination is largely widespread among Caesalpinioideae and the Fabaceae in general (Arroyo 1981).

In the present study, $C$. crista has a suite of floral characteristics conforming to melittophily. These include diurnal anthesis, slight fragrance, zygomorphy, yellow petals, with a flag petal displaying a conspicuous nectar guide, and the presence of nectar with a high sugar concentration (Faegri \& van der Pijl 1979). C. echinata also possesses the same characteristics as a melittophilous species (Borges et al. 2009). High nectar sugar concentration is reported in Pongamia pinnata (Raju \& Rao 2006). In C. eriostachys, the flowers are yellow and the flag petal with nectar guide absorbs ultraviolet light (Jones \& Buchmann 1974). The anthers absorb UV light while the filaments act as reflectors (Borges et al. 2009). In C. crista, the nectar guide displayed by the flag petal may be visible in ultraviolet light and Shi-Jin et al. (2004) also felt the same. The petals, sepals and anthers are all yellow and they could effectively be perceived by bees (Percival 1965). Further, extra-floral nectar along the rachis is an additional attractant and is easily perceivable by bees. The pollinator attraction appears to be a consequence of combination of floral and extra-floral nectar apart from the primary floral characteristics (Shi-Jin et al. 2004). Restricted access to nectar through openings between the bases of three upper stamens indicates resource protection, a trait that Arroyo (1981) attributed to the more advanced genera of Caesalpinioideae. This floral specialization to restrict nectar is an important trait in melittophilous species in which bees with their skills handle the flowers efficiently to access the nectar in C. crista. Similar floral specialization to protect nectar resource from unwanted foragers has also been reported in C. echinata and also in other species of Caesalpinia (Li et al. 2004).

In the present study, C. crista with melittophilous characteristics is pollinated almost exclusively by bees, especially carpenter bees. Further, a butterfly species, Catopsilia pomona also visits the flowers for nectar suggesting that the plant does not exclude visits by other types of visitors or occasional pollinators. Borges et al. (2009) also reported that the melittophilous species, $C$. echinata does not exclude infrequent visits by other types of visitors or occasional pollinators such as butterflies and hummingbirds. Further, wind also plays an important role in the pollination of $C$. crista. The floral characteristics such as free petals, fully exposed stamens with dry and powdery pollen grains and hairy stigma favour anemophily. The locations of this plant are windy during the rainy season and wind drives the pollen effectively. The prolific growth and near synchronous flowering at population level contribute to pollen availability in huge quantities and enable anemophily as an effective mode of pollination. The function of a pollination system involving both bees and wind as vectors of pollen transfer is referred to as 'ambophily' (Culley et al. 2002) and this pollination system is adaptive for $C$. crista to set fruit in the absence of bees. Li et al. (2004) and Shi-Jin et al. (2004) reported that $C$. crista in China is ambophilous and the biotic pollinators included honey bees, carpenter bees, wasps, flies, ants, butterflies and coleopterans. Therefore, C. crista is characteristically ambophilous and 
utilizes autochthonous pollinators, especially bees for pollination. The bees are highly efficient in transferring pollen and the same is realized in the body washings of bees which were collected while foraging at the flowers.

In Caesalpinia genus, both self-incompatibility and self-compatibility has been reported by different workers in the studied taxa. The self-incompatible species include C. eriostachys (Bawa \& Webb 1984; Bullock 1985), C. coriaria, C. sclerocarpa (Bullock 1985), C. caladenia, C. pulcherrima (Bullock 1985) and C. echinata (Borges et al. 2009). The self-compatible species include $C$. calycina (Lewis \& Gibbs 1999), C. brevifolia, C. echinata, C. sappan and C. spinosa (Roubik 1995). Further, Bawa \& Webb (1984) suggested that reports of self-incompatibility in caesalpinioid species should be reassessed; the selfincompatibility in the reported taxa is functional during post-zygotic stage only. In C. crista, the flowers are bisexual, self-compatible and self-pollinating but it is principally out-crossing and the same is realized in the hand-pollination tests. The difference in fruit set rate in autogamy and geitonogamy could be related to minor genetic differences between flowers of the same plant (Roubik 1995). The high pollen-ovule ratio evidenced in this plant also favours out-crossing, sensu Cruden (1977). The ability to set fruit through self- and cross-pollination facilitates $C$. crista for achieving genetic variation in order to survive in its natural harsh environment where insects are not reliable throughout the duration of flowering season. The long period of flowering season is an additional advantage for more fruit set. Despite the ambophilous pollination syndrome, mixed breeding system and extended flowering season, natural fruit set does not exceed $10 \%$. The low fruit set evidenced in this plant is partly due to flower-feeding by the beetle, Mylabris phalerata; its flower-feeding rate stands at $23 \%$ at the study area. The extended flowering and nutrient resource constraints appear to be regulating the fruit set rate in C. crista. Bawa \& Webb (1984) and Lewis \& Gibbs (1999) reported low fruit set rates in $C$. pluviosa (4\%), C. calycina (12.7\%), C. gilliesii (12\%) and C. pulcherrima (13\%). These authors also mentioned that in C. eriostachys, fruit set is reduced due to high rates of abortion of flowers and immature fruits. Stephenson (1981) reported a low fruit set rate in C. echinata due to a high rate of abortion as a consequence of pollination failure, availability and allocation of nutrient reserves, sexual selection, or predation, among other factors. He found a high incidence of seed and ovule abortion and seed predation even among fruits that successfully developed as well as the presence of lepidopteran larva inside many flowers. Leite (2006) noted a high percentage of fruits without developed seeds in $C$. pyramidalis. In C. crista, bud, flower and fruit abortion is completely absent and the fruit set rate evidenced in this plant is a consequence of flower-feeding by the beetle, high investment in flower production over a period of three months at individual level and the level of nutrients availability to the plant during fruiting period.

In C. crista, the fruits mature within six weeks and each fruit produces a single seed due to single-ovuled flowers. The fruits are indehiscent and disperse in that form in tidal waters. They are water-buoyant but they do not disperse far away from the parental sites since the species is restricted to the landward side. The fruit pericarp being leathery in nature gradually disintegrates in water releasing the seeds into water or soil. The seeds are also water-buoyant but their dispersal occurs during the summer season when the soil is relatively exposed and partly wet. They remain dormant throughout the summer season during which they may be subjected to desiccation and predation by soil insects; the healthy and viable seeds germinate and produce new plants during the rainy season. Field studies indicated the emergence of a few new plants each year suggesting that $C$. crista has recruitment problems. Therefore, studies on seed predation and viability are suggested in order to understand the seed and seedling ecology of this plant.

\section{CONCLUSIONS}

Caesalpinia crista as a mangrove associate is an important constituent in the Coringa Mangrove Forest. It has its share in soil binding and stabilization of the floor in the landward marginal areas. The timing of the flowering event and the intense flowering facilitates the local bees to use the flowers as important sources of pollen and nectar. The hermaphroditic sexual system, self-compatibility, mixed breeding system and anemophily is inevitable for the plant to fruit in the presence or absence of pollen vectors since the latter are not reliable in the harsh environment that exists in the mangrove ecosystem. The dual pollination system of ambophily appears to have evolved over a period of time to cope with the adverse habitat conditions in order to build up the population and expand the distribution in the landward areas. The patchy distribution or the occurrence of pure stands of $C$. crista in essence sustains the local bees for almost half of the year and its habitat provides the nesting sites for the soil burrowing bees. 
Therefore, the information provided in this paper forms the basis for further work on seed ecology and seedling establishment patterns within the mangrove forest ecosystem in relation to salinity and nutrient levels in the soil.

\section{REFERENCES}

Ali, A. (1932). Flower birds and bird-flowers in India. Journal of the Bombay Natural History Society 35: 573-605.

Arroyo, S.C. (1981). Systematic anatomical studies on Amaryllidaceae including morphological, ecological, cytological and phytogeographical considerations. PhD Thesis, University of Reading, Reading, U.K.

Bawa, K.S. \& C.J. Webb (1984). Flower, fruit and seed abortion in tropical tropical forest trees: implications for the evolution of paternal and maternal reproductive patterns. American Journal of Botany 71: 736-751.

Borges, L.A., M.S. Sobrinho \& A.V. Lopes (2009). Phenology, pollination, and breeding system of the threatened tree Caesalpinia echinata Lam. (Fabaceae), and a review of studies on the reproductive biology in the genus. Flora Morphology, Distribution and Functional Ecology of Plants 204: 111-130; http://dx.doi. org/10.1016/j.flora.2008.01.003

Bullock, S. (1985). Breeding systems in the flora of a tropical deciduous forest in Mexico. Biotropica 17: 287-301.

Cocucci, A.A., A. Galetto \& A. Sersic (1992). El syndrome floral de Caesalpinia gilliesii (Fabaceae-Caesalpiniodeae). Darwiniana 31 111-135.

Cruden, R.W. (1977). Pollen-ovule ratios: a conservative indicator of breeding systems in flowering plants. Evolution 31: 32-46; http:// dx.doi.org/10.2307/2407542

Cruden, R.W. \& S.M. Hermann-Parker (1979). Butterfly pollination of Caesalpinia pulcherrima with observations on a psychophilous syndrome. Journal of Ecology 67: 155-168.

Culley, T.M., S.G. Weller \& A.K. Sakai (2002). The evolution of wind pollination in angiosperms. Trends in Ecology and Evolution 17: 361-369; http://dx.doi.org/10.1016/S0169-5347(02)02540-5

Dafni, A., P.G. Kevan \& B.C. Husband (2005). Practical Pollination Biology. Enviroquest Ltd., Ontario, 583pp.

Faegri, K \& L. van der Pijl (1979). The Principles of Pollination Ecology. Pergamon Press, New York, 244pp.
Jabbar, A., M.A. Zaman, Z. Iqbal, M. Yaseen \& A. Shamim (2007). Anthelmintic activity of Chenopodium album (L.) and Caesalpinia crista (L.) against trichostrongylid nematodes of sheep. Journal of Ethnopharmacology 114: 86-91; http://dx.doi.org/10.1016/j. jep.2007.07.027

Jones, C.E \& S.L. Buchmann (1974). Ultraviolet floral patterns as functional orientation cues in hymenopterous pollination systems. Animal Behaviour 22: 481-485; http://dx.doi.org/10.1016/S00033472(74)80047-3

Koch, C.U., J.E. Gutierrez, A. Rodriguez \& O. Helversen (2004). Bat pollination in a cuban ultramafic endemic: Caesalpinia bahamensis Lam. subsp. orientensis Borhidi, pp. 243-253. In: Boyd, R.S, A.J.M. Barker \& J. Proctor (eds). Ultramatic Rocks: Their Soils, Vegetation and Fauna. Science Reviews, St. Albans.

Leite, A.V.L. (2006). Biologia Reprodutiva em Plantas da Caatinga: Evidencias de um Padrao. PhD Thesis, Universidade Federal de Pernambuco, Brazil.

Lewis, G. \& P. Gibbs (1999). Reproductive biology of Caesalpinia calycina and C. pluviosa (Leguminosae) of the Caatinga of north eastern Brazil. Plant Systematics \& Evolution 217: 43-53.

Lewis, G.P. (1998). Caesalpinia: a revision of the PoincianellaErythorstemon Group. Richmond. Royal Botanical Gardens, Kew.

Lewis, G.P., B.B. Simpson \& J.L. Neff (2000). Progress in understanding the reproductive biology of the Caesalpinioideae (Leguminosae), pp. 65-78. In: Herendeen, P.S. \& A. Bruneau (eds.). Advances in Legume Systematics - Vol. 9. Royal Botanic Garden, Kew.

Li, S-J., D-X. Zhang, L. Li. \& Z-Y. Chen (2004). Pollination ecology of Caesalpinia crista (Leguminosae: Caesalpiniodeae). Acta Botanica Sinica 26: 271-278.

Percival, M. (1965). Floral Biology. Pergamon Press, New York, 243pp. Raju, A.J.S. \& S.P. Rao (2006). Explosive pollen release and pollination as a function of nectar-feeding activity of certain bees in the biodiesel plant, Pongamia pinnata (L.) Pierre (Fabaceae). Current Science 90: 960-967.

Roubik, D.W. (1995). Pollination of Cultivated Plants in the Tropics. FAO Agricultural Services Bulletin 118, 198pp.

Shi, Jin, L.I., Z. Dian-Xiang, L.L. Lin \& C. Zhong-yi (2004). Pollination ecology of Caesalpinia crista (Leguminosae: Caesalpinioideae). Acta Botanica Sinica 46: 271-278.

Stephenson, A.G. (1981). Flower and fruit abortion: proximate causes and ultimate functions. Annual Review of Ecology and Systematics 12: 253-279; http://dx.doi.org/10.1146/annurev. es.12.110181.001345

Tomlinson, P.B. (1986). The Botany of Mangroves. Cambridge University Press, New York, 413pp.

Vogel, S. (1990). Radiacion adaptive del syndrome floral en las familias neotropicales. Boletin de la Academia Nacional de Ciencias 59: 5-30. 